\title{
Exercise Training Improved Pulmonary Gas Exchange Abnormalities in Pulmonary Hypertension due to Heart Failure: A Case Report
}

Danilo Marcelo Leite do Prado, ${ }^{1,2}$ Enéas Antônio Rocco, ${ }^{3}$ Júlia de Paiva Fonseca de Campos, ${ }^{3}$ Thais Pellegrino Miranda, ${ }^{3}$ Amanda Barbuio Teixeira, ${ }^{3}$ Michele Staroste, ${ }^{3}$ Emmanuel Gomes Ciolac ${ }^{1}{ }^{\circledR}$

São Paulo State University (UNESP), School of Sciences, Physical Education Department, Exercise and Chronic Disease Research Laboratory (ECDR), Bauru, ${ }^{1}$ SP-Brazil.

Ultra Sports Science, ${ }^{2}$ São Paulo, SP - Brazil.

Hospital Samaritano, Departamento de Reabilitação Cardiorrespiratória, ${ }^{3}$ São Paulo, SP - Brazil.

\begin{abstract}
Heart failure (HF) is the most common cause of pulmonary hypertension $(\mathrm{PH})$, and reduced exercise capacity and exertional dyspnea are the most frequent concerns in patients with PH-HF. Indeed, carbon dioxide end-tidal partial pressure $\left(\mathrm{PETCO}_{2}\right)$ during exercise is a well-established noninvasive marker of ventilation/perfusion ratio in $\mathrm{PH}$. We aimed to evaluate the effect of aerobic exercise training on $\mathrm{PETCO}_{2}$ response during exercise in a 59-year-old woman with $\mathrm{PH}$ secondary to idiopathic dilated cardiomyopathy. The patient with chronic fatigue and dyspnea at mild-to-moderate efforts was admitted to a cardiorespiratory rehabilitation program and had her cardiorespiratory response to exercise assessed during a cardiopulmonary exercise testing performed before and after three months of a thrice-weekly aerobic exercise training program. Improvements in aerobic capacity $(23.9 \%)$ and endurance time $(37.5 \%)$ and reduction in ventilatory inefficiency $(-20.2 \%)$ was found after intervention. Post-intervention improvements in $\mathrm{PETCO}_{2}$ at ventilatory anaerobic threshold $(23.3 \%)$ and change in $\mathrm{PETCO}_{2}$ kinetics pattern, with progressive increases from rest to peak of exercise, were also found. Patient also improved breathing pattern and
\end{abstract}

\section{Keywords}

Aerobic Capacity; Exercise Test; Cardiovascular Diseases; Pulmonary Gas Exchange; High Frequency Ventilation. timing of ventilation. This case report demonstrated for the first time that aerobic exercise training might be able to improve $\mathrm{PETCO}_{2}$ response during exercise in a patient with $\mathrm{PH}-\mathrm{HF}$.

\section{Introduction}

Heart failure (HF) is the most common cause of pulmonary hypertension $(\mathrm{PH})^{1}$ and is associated with increased morbidity and mortality. ${ }^{1,2}$ Exertional dyspnea and reduced exercise capacity are the most frequent concerns in patients with $\mathrm{PH}$ due to $\mathrm{HF}(\mathrm{PH}-$ $\mathrm{HF}),{ }^{2}$ The key physiological mechanism in $\mathrm{PH}$-related exertional dyspnea is a lung vasculature abnormality due to excessive pulmonary vascular resistance, which attenuates cardiac output response to exercise. ${ }^{3}$ Noteworthy, patients with PH show a sharp increase in physiologic dead space and hence reduced gas exchange efficiency. ${ }^{3}$ Indeed, patients with HF often display ventilatory abnormalities likely related to dysregulation in peripheral control (i.e., impaired skeletal muscle ergoreflex and increased peripheral chemoreceptor sensitivity). ${ }^{4-6}$

Cardiopulmonary exercise testing (CPX) is an useful tool for assessing severity and prognosis in cardiorespiratory disease. ${ }^{7}$ Carbon dioxide end-tidal partial pressure $\left(\mathrm{PETCO}_{2}\right)$ during $\mathrm{CPX}$ is a wellestablished noninvasive marker of ventilation/perfusion ratio in patients with lung and heart diseases. ${ }^{8}$ Indeed, the $\mathrm{PETCO}_{2}$ decrease from rest to ventilatory anaerobic threshold (VAT) during CPX is associated with pulmonary gas exchange abnormalities in patients with $\mathrm{PH} .{ }^{9}$

Mailing Address: Emmanuel Ciolac

Av. Eng. Luiz Edmundo Carrijo Coube, 14-01. Postal Code: 17033-360, Bauru, SP - Brazil.

E-mail: emmanuel.ciolac@unesp.br 
Therapeutic strategies are available for treating primary $\mathrm{PH}$; however, the same does not occur for $\mathrm{PH}-\mathrm{HF}$, whereas target therapy agents have failed to demonstrate benefit or have even been harmful. ${ }^{1,2}$ Although exercise training is a well-established nonpharmacological therapy for $\mathrm{HF},{ }^{10}$ its effect on patients with PH-HF, particularly on $\mathrm{PETCO}_{2}$ response during exercise, is unknown. Therefore, our aim was to report the effect of aerobic exercise training on $\mathrm{PETCO}_{2}$ response during exercise in a patient with PH-HF.

\section{Case Report}

\section{Patient's characteristic and evaluation}

A 59-year-old sedentary female (weight: $86 \mathrm{~kg}$, height: $162 \mathrm{~cm}$ ) with PH secondary to idiopathic dilated cardiomyopathy was admitted for cardiorespiratory rehabilitation in the TotalCare clinic, São Paulo, Brazil. Her comorbidities included systemic hypertension, diabetes, and dyslipidemia. No lower limb edema or increased jugular venous pressure, and resting blood pressure and heart rate of 140/100 $\mathrm{mmHg}$ and $60 \mathrm{bpm}$, respectively, were found during physical examination. Patient had regular heart rhythm with mitral regurgitation and clear breath sounds during auscultation. Her symptoms were chronic fatigue and dyspnea at mild-to-moderate efforts. She had never participated in any exercise program and had no history of hospitalization associated with HF.

Normal sinus rhythm and left branch bundle block were showed during resting electrocardiography. Global left ventricular (LV) hypokinesia with mildly impaired overall systolic function (ejection fraction: 37\%), LV dilatation, and moderate PH (PASP: 55 $\mathrm{mmHg}$ ) were showed during echocardiogram. Echocardiography diagnosis of $\mathrm{PH}$ was obtained through right ventricular systolic pressure (RVSP). The echocardiographic assessment was evaluated by the maximal tricuspid regurgitation velocity and the systolic gradient between the right ventricle and the right atrium was calculated. ${ }^{11}$

Baseline medications included carvedilol, hydrochlorothiazide, spironolactone, amlodipine, losartan, acetylsalicylic acid, and synvastatin, and no changes occurred during the previous three month before and throughout the study. The study was approved by the local Ethics Committee (CAEE :26442619.9.0005533) and patient signed an informed consent form.
A symptom-limited maximal CPX was carried out on treadmill (Centurion model 300; Micromed, Brazil) using a Balke modified protocol, ${ }^{12}$ at controlled room temperature $\left(20-23^{\circ} \mathrm{C}\right), 2$ and 3 days before beginning and after ending the exercise program, respectively. Gas exchange and ventilatory variables were measured breath-by-breath throughout the test by a computerized system (Cortex model III B; Leipzig, Germany) and expressed as $30 \mathrm{sec}$ averages, as previously described. ${ }^{12}$ Heart rate was continuously recorded by 12-lead ECG (Elite Ergo PC; Micromed, Brazil) during resting, exercise, and recovery phases of CPX. VAT, peak oxygen consumption $\left(\mathrm{VO}_{2}\right.$ peak), oxygen uptake efficiency slope (OUES), ventilatory equivalent of $\mathrm{CO}_{2}$ production $\left(\mathrm{V}_{\mathrm{E}} /\right.$ $\mathrm{VCO}_{2}$ ) slope, noninvasive estimate for physiologic dead space to tidal volume ratio $\left(\mathrm{V}_{\mathrm{D}} / \mathrm{V}_{\mathrm{T}}\right)$, $\mathrm{PETCO}_{2}$ pattern, and ventilatory pattern analysis (i.e., breathing frequency $(\mathrm{BF})$, tidal volume $\left(\mathrm{V}_{\mathrm{T}}\right)$, expiratory time $\left(\mathrm{T}_{\mathrm{E}}\right)$, inspiratory time $\left(\mathrm{T}_{\mathrm{I}}\right)$, total respiratory time (TOT), mean inspiratory flow $\left(\mathrm{V}_{\mathrm{T}} / \mathrm{T}_{\mathrm{I}}\right)$, and mean expiratory flow $\left(\mathrm{V}_{\mathrm{T}} / \mathrm{T}_{\mathrm{E}}\right)$ ) were assessed during $\mathrm{CPX} .^{12}$ As previously described, VAT was considered the point at which ventilatory equivalent of $\mathrm{O}_{2}\left(\mathrm{VE} / \mathrm{VO}_{2}\right)$ reached the minimum value and began to rise without a concomitant rise in $\mathrm{VE} / \mathrm{VCO}_{2}{ }^{14} \mathrm{VO}_{2}$ peak was defined as the maximum $\mathrm{VO}_{2}$ attained at the end of the exercise period, at which time the patient had reached his/her maximum level of exhaustion (Borg's rating of perceived exertion scale). ${ }^{13}$

\section{Exercise Training Program}

A thrice-weekly supervised exercise training program were performed for three months at the TotalCare clinic's cardiorespiratory rehabilitation center. Exercise sessions included warm-up ( $5 \mathrm{~min}$ ), aerobic ( $50 \mathrm{~min}$ ), and cool-down (5 min) exercises. Aerobic exercise was a treadmill walking at the heart rate corresponding to the VAT during CPX $( \pm 5$ $\mathrm{bpm}$ ). Heart rate was monitored throughout the session to ensure that patient exercised within the limits of intensity. The participant attended $90 \%$ of the programmed exercise sessions (33 sessions) and did not perform any exercise at home or any other exercise modality.

\section{Outcomes}

Severe impairment in cardiorespiratory fitness $\left(<50 \%\right.$ of age predicted peak $\left.\mathrm{VO}_{2}\right)$, reduced gas exchange efficiency, and abnormal $\mathrm{PETCO}_{2}$ pattern with progressive decreases were observed at baseline (Table 1 and Figure 1A). 
(A)

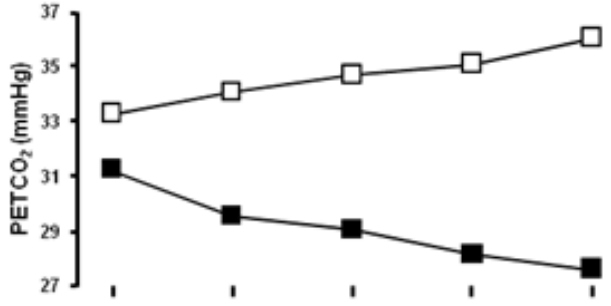

(C)

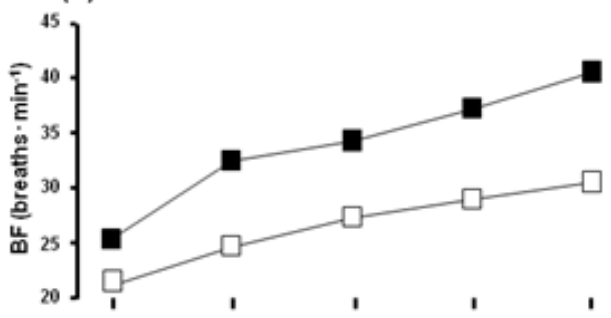

(E)

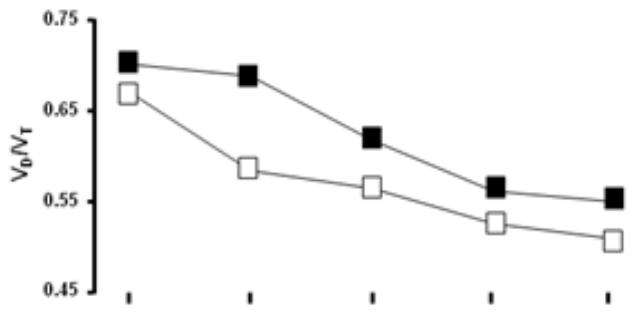

(G)
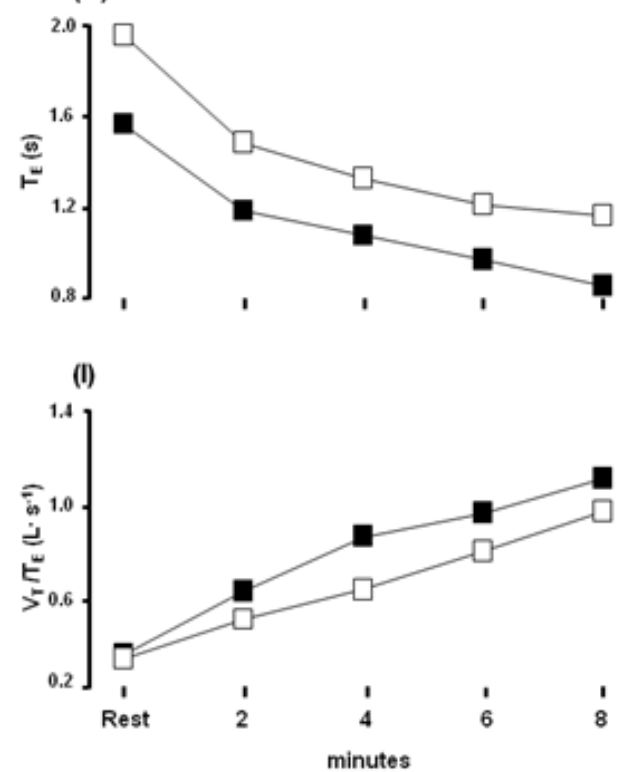

Pre $\square$ Post

(B)

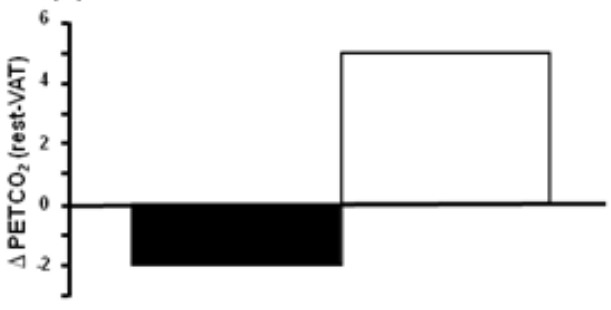

(D)

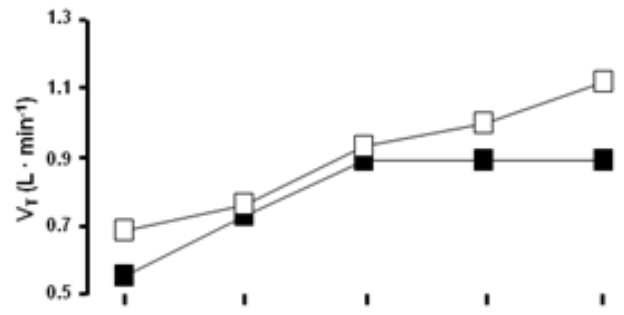

(F)

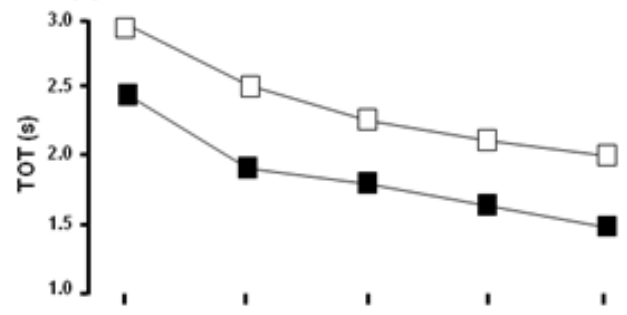

(H)

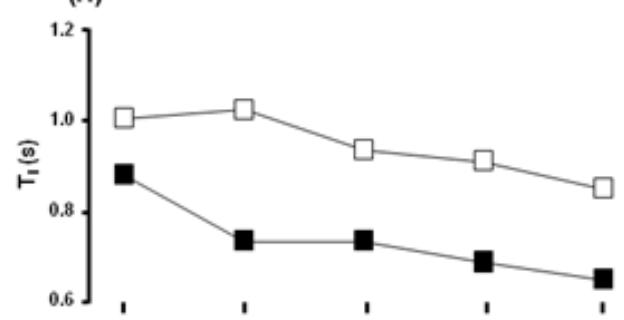

(J)

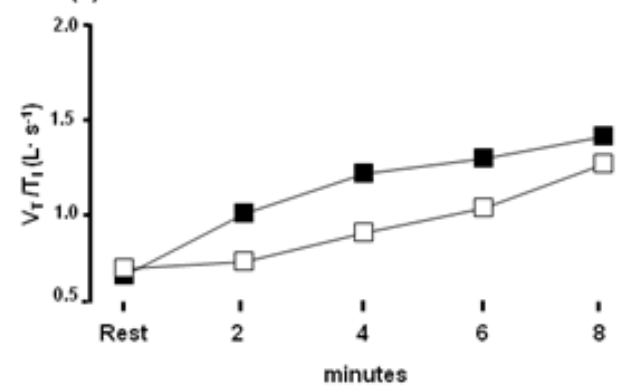

Figure 1 - Ventilatory response to cardiopulmonary exercise testing before (pre) and after (post) 3 months of aerobic exercise training. A: Carbon dioxide end-tidal partial pressure (PETCO2), B: Carbon dioxide end-tidal partial pressure change ( $\triangle P E T C O 2)$ from rest to ventilatory anaerobic threshold (VAT), C: breath frequency (BF), D: tidal volume (VT), E: physiologic dead space to tidal volume ratio (VD/ $V T), F$ : total respiratory time (TOT), G: expiratory time (TE), H: inspiratory time (TI), I: mean inspiratory flow (VT/TI), J: mean expiratory flow $(V T / T E)$. 
After three month of aerobic exercise training, patient showed an increase in body mass $(1 \mathrm{~kg})$, peak $\mathrm{VO}_{2}(23.9 \%)$, peak $\mathrm{O}_{2}$ pulse $(24.1 \%)$, and endurance time $(33.3 \%)$, as well as in $\mathrm{VO}_{2}$ at VAT (38.1\%) and OUES (14.5\%) (Table 1). Patient also showed lower $\mathrm{V}_{\mathrm{E}} \mathrm{VCO}_{2}$ slope levels (Table 1). $\mathrm{PETCO}_{2}$ analysis during $\mathrm{CPX}$ showed increased $\mathrm{PETCO}_{2}$ at VAT $(23.3 \%)$ and a change in $\mathrm{PETCO}_{2}$ kinetics pattern with progressive increases from rest to peak of exercise when compared to pre-intervention (Figure 1A and 1B). Patient also improved breathing pattern (Figure $1 \mathrm{C}$ and 1D) and timing of ventilation (Figure 1G, 1H, 1I, and 1J).

\section{Discussion}

Progressive increase in $\mathrm{PETCO}_{2}$ from resting to VAT (nearly 5-8 $\mathrm{mmHg}$ ), followed by its maintenance or slight increase up to the onset of respiratory compensation point and its progressive decrease from respiratory compensation point to maximal effort, is expected in healthy subjects during CPX. ${ }^{12}$ In contrast, our data showed progressive decreases in $\mathrm{PETCO}_{2}$ from resting to VAT and maximal effort at baseline (Figures 1A and 1B), which is in accordance with a previous study assessing the $\mathrm{PETCO}_{2}$ response in patients with primary $\mathrm{PH} .{ }^{9}$ Indeed, the abnormal $\mathrm{PETCO}_{2}$ response was directly associated with disease severity. ${ }^{9}$

Physiological mechanisms involved in the altered $\mathrm{PETCO}_{2}$ pattern found at baseline may include: (1) ventilation-perfusion inequalities due to ventilated alveoli hypoperfusion, resulting in increased physiologic dead space $\left(\mathrm{V}_{\mathrm{D}} / \mathrm{V}_{\mathrm{T}}\right)$ and (2) increased acidosis at lower work rates, resulting in augmentation of ventilation drive induced by higher levels of hydrogen ion $\left(\mathrm{H}^{+}\right) .{ }^{9}$ For instance, the increased pulmonary vascular resistance in patients with $\mathrm{PH}$ may blunt cardiac output response during exercise, which results in reduced $\mathrm{O}_{2}$ transport to working muscle, thereby increasing the contribution of anaerobic glycolysis to exercise. Indeed, patients with HF demonstrate impaired skeletal muscle metabolism, which reduces mitochondrial oxidative capacity. ${ }^{13}$ Thus, it is possible that both pulmonary gas exchange and muscle metabolism abnormalities may be involved in the impaired baseline $\mathrm{PETCO}_{2}$ response during exercise in the patient with PH-HF.

In contrast, to the best of our knowledge, the present report showed for the first time that three months of aerobic exercise training might improve $\mathrm{PETCO}_{2}$ response to exercise in a patient with $\mathrm{PH}-\mathrm{HF}$, as shown by the sharp increase in $\mathrm{PETCO}_{2}$ from rest to VAT (Figure
1B), as well as by the increased PETCO $_{2}$ levels at both VAT and peak of exercise (Table 1). This result is in line with a previous study demonstrating the effectiveness of aerobic exercise training for improving $\mathrm{PETCO}_{2}$ response in coronary artery disease patients. ${ }^{13}$

It is known that exercise training improves muscle oxidative metabolism during exercise in individuals with $\mathrm{HF}$ (e.g., increased $\mathrm{O}_{2}$ uptake and arteriovenous $\mathrm{O}_{2}$ difference, lower phosphocreatine depletion, lower increase in adenosine diphosphate, and decreased lactate accumulation). ${ }^{14}$ In addition, training-induced improvements in ventilation efficiency during exercise are, at least in part, due to improvements in muscle receptor reflexes and skeletal muscle metabolism in individuals with HF. ${ }^{15,16}$ In this context, it can be suggested that a training-induced improvement in muscle aerobic metabolism may be reduced acidosisrelated ventilatory stimulus during $\mathrm{CPX}$, and thus may be associated with the improved $\mathrm{PETCO}_{2}$ response after training in the present study. The improvements in both $\mathrm{VO}_{2}$ at VAT and OUES suggest an increase in muscle aerobic capacity and thus support this hypothesis.

Improvements in gas exchange efficiency and breathing pattern may be induced by the reduction of physiologic dead space ventilation and may also be involved in the improved $\mathrm{PETCO}_{2}$ response after training. ${ }^{12} \mathrm{In}$ this context, the reduced $\mathrm{V}_{\mathrm{E}} \mathrm{VCO}_{2}$ slope, $\mathrm{V}_{\mathrm{D}}$ / $\mathrm{V}_{\mathrm{T}^{\prime}}$ and tachypneic (BF) and shallow pattern of breathing $\left(\mathrm{T}_{\mathrm{E}}\right.$ and $\left.\mathrm{T}_{\mathrm{I}}\right)$ after training support this hypothesis. In fact, the reduced $\mathrm{V}_{\mathrm{T}} / \mathrm{T}_{\mathrm{I}}$ and $\mathrm{V}_{\mathrm{T}} / \mathrm{T}_{\mathrm{E}}$ after training indicate a decrease in neuromuscular inspiratory and expiratory drive, respectively. It is important to note that breathing pattern has a significant influence in the $\mathrm{V}_{\mathrm{D}} / \mathrm{V}_{\mathrm{T}}$ ratio during exercise. Specifically, a tachypneic breathing pattern during exercise increases $\mathrm{V}_{\mathrm{D}} / \mathrm{V}_{\mathrm{T}}$ ratio and decreases $\mathrm{PETCO}_{2}$ levels. ${ }^{17}$ Moreoever, higher levels of breathing frequency are closely related to decreases in expiratory time and, as a consequence, in premature cessation and greater $\mathrm{PETCO}_{2}$ increase during progressive exercise. ${ }^{17}$ Thus, the decrease in breathing frequency and the increase in expiratory time found after exercise training may also be associated with the improved $\mathrm{PETCO}_{2}$ response during follow-up in the present study. Interestingly, peripheral chemoreflex control was normalized after exercise training in a rabbit model of heart failure, ${ }^{18}$ suggesting that it may be associated with the improvement in ventilation efficiency.

It is noteworthy that the patient also reported an improvement in exertional dyspnea sense after training, 
which is in line with the improved exercise capacity, as shown by the training-induced increase in exercise time during CPX. In conjunction, these improvements may result in an increased quality of life.

The echocardiography used for assessing $\mathrm{PH}$ is a limitation of the present study. However, we used sequential assessments to confirm the diagnosis. The assessment of only one patient during the follow-up is also a limitation that should be acknowledged.

In summary, this case report showed for the first time that the impaired $\mathrm{PETCO}_{2}$ response to exercise in PH-HF might be improved by three months of a thriceweekly aerobic exercise training program. Given that $\mathrm{PETCO}_{2}$ is a noninvasive marker of ventilation/perfusion ratio $^{8}$ and that its abnormal response during $\mathrm{CPX}$ is associated with pulmonary gas exchange abnormalities in patients with $\mathrm{PH}^{9}$ the present results suggest that aerobic exercise training may be an important tool for improving pulmonary gas exchange abnormalities in patients with $\mathrm{PH}-\mathrm{HF}$.

\section{Author Contributions}

Conception and design of the research: do Prado DM, Fonseca de Campos JP, Miranda TP. Teixeira AB, Staroste M. Acquisition of data: do Prado DM, Fonseca de Campos JP, Miranda TP. Teixeira AB, Staroste M. Analysis and

\section{References}

1. Rosenkranz S, Gibbs JS, Wachter R, De Marco T, Vonk-Noordegraaf A, Vachiery JL. Left ventricular heart failure and pulmonary hypertension. Eur Heart J. 2016 2016;37(12):942-54.

2. Guazzi M, Borlaug BA. Pulmonary hypertension due to left heart disease. Circulation. 2012 2012;126(8):975-90.

3. Sun XG, Hansen JE, Oudiz RJ, Wasserman K. Exercise pathophysiology in patients with primary pulmonary hypertension. Circulation. 2001 2001;104(4):429-35.

4. Olson TP, Joyner MJ, Johnson BD. Influence of locomotor muscle metaboreceptor stimulation on the ventilatory response to exercise in heart failure. CircHeart Fail. 2010;3(2):212-9.

5. Guimaraes GV, Belli JF, Bacal F, Bocchi EA. Behavior of central and peripheral chemoreflexes in heart failure. Arq Bras Cardiol. 2011;96(2):161-7.

6. Belli JF, Bacal F, Bocchi EA, Guimaraes GV. Ergoreflex activity in heart failure. Arq Bras Cardiol. 2011;97(2):171-8.

7. Corra U, Agostoni PG, Anker SD, et al. Role of cardiopulmonary exercise testing in clinical stratification in heart failure. A position paper from the Committee on Exercise Physiology and Training of the Heart Failure Association of the European Society of Cardiology. Eur J Heart Fail. 2018;20(1):3-15.

8. Hansen JE, Ulubay G, Chow BF, Sun XG, Wasserman K. Mixed-expired and end-tidal $\mathrm{CO} 2$ distinguish between ventilation and perfusion defects during exercise testing in patients with lung and heart diseases. Chest. 2007;132(3):977-83.

9. Yasunobu Y, Oudiz RJ, Sun XG, Hansen JE, Wasserman K. End-tidal PCO2 abnormality and exercise limitation in patients with primary pulmonary hypertension. Chest. 2005;127(5):1637-46.

10. Corra U, Giannuzzi P, Adamopoulos S, et al. Executive summary of the position paper of the Working Group on Cardiac Rehabilitation and interpretation of the data: do Prado DM, Rocco EA, Ciolac EG. Writing of the manuscript: do Prado DM, Ciolac EG. Critical revision of the manuscript for intellectual content: do Prado DM, Rocco EA, Ciolac EG.

\section{Potential Conflict of Interest}

No potential conflict of interest relevant to this article was reported.

\section{Sources of Funding}

EGC was supported by Conselho Nacional de Desenvolvimento Científico e Tecnológico (CNPq \#303399/2018-0) during this study.

\section{Study Association}

This study is not associated with any thesis or dissertation work.

\section{Ethics Approval and Consent to Participate}

This study was approved by the Ethics Committee of the Hospital Samaritano under the protocol number 26442619.9.0005533. All the procedures in this study were in accordance with the 1975 Helsinki Declaration, updated in 2013. Informed consent was obtained from all participants included in the study.

Exercise Physiology of the European Society of Cardiology (ESC): core components of cardiac rehabilitation in chronic heart failure. Prev Card Reha Exerc Physiol. 2005;12(4):321-5.

11. Sciomer S, Badagliacca R, Fedele F. Pulmonary hypertension: echocardiographic assessment. Ital Heart J. 2005;6(10):840-5.

12. Prado DML, Rocco EA, Silva AG, Rocco DF, Pacheco MT, Silva PF, et al. Effects of continuous vs interval exercise training on oxygen uptake efficiency slope in patients with coronary artery disease. Braz J Med Biol Res. 2016;49(2):e4890

13. Rocco EA, Prado DM, Silva AG, Rocco DF, Pacheco MT, Silva PF, et al et al. Effect of continuous and interval exercise training on the PETCO2 response during a graded exercise test in patients with coronary artery disease. Clinics (Sao Paulo). 2012;67(6):623-8.

14. Adamopoulos S, Coats AJ, Brunotte F, Arnolda L, Mayer T, Thompson $\mathrm{CH}$, et al.et al. Physical training improves skeletal muscle metabolism in patients with chronic heart failure. J Am Coll Cardiol. 1993;21(5):1101-6.

15. Van Laethem C, Van De Veire N, De Backer G, Bihija S, Seghers T, Cambier D, et al. Response of the oxygen uptake efficiency slope to exercise training in patients with chronic heart failure. EuJ Heart Fai. 2007;9(6-7):625-9.

16. Piepoli M, Clark AL, Volterrani M, Adamopoulos S, Sleight P, Coats AJ Contribution of muscle afferents to the hemodynamic, autonomic, and ventilatory responses to exercise in patients with chronic heart failure: effects of physical training. Circulation. 1996;93(5):940-52.

17. Prado DM, Braga AM, Rondon MU, Azevedo LF, Matos LDN, Negrão CE.et al. [Cardiorespiratory responses during progressive maximal exercise test in healthy children]. Arq Bras Cardiol. 2010;94(4):493-9.

18. Li YL, Ding Y, Agnew C, Schultz HD. Exercise training improves peripheral chemoreflex function in heart failure rabbits. J Appl Physiol. (1985). 2008;105(3):782-90. 